suppress ineffective attempts to cough and to relieve general distress. Tolerance is not a problem, and it is rarely necessary to increase the dose. Such a regimen reduces the need for suction of pharyngeal and tracheal secretions. It is a time when support and companionship are of paramount importance. Though the doctor may feel powerless in the face of death, his continued attendance (indicating that he will stand by the patient no matter what happens) is of inestimable value. After the first bad coughing or choking attack the patient will usually need carefully expressed reassurance that he will not be left to die alone or choke to death on his own secretions. Death generally occurs as a result of varying combinations of. aspiration pneumonitis, hypostatic bronchopneumonia, and carbon-dioxide narcosis, and both the family and nurses may need to have the inappropriateness of antibiotic treatment explained.

1 Walshe, F, and Walshe, J, Diseases of the Nervous System, 11th edn, p 256. Edinburgh, Livingstone, 1970.

2 Mulder, D W, Modern Treatment, 1966, 3, 243.

3 Norris, F H, et al, Neurology, 1974, 24, 721.

4 Mulder, D W, and Espinosa, in Motor Neuron Diseases, eds F H Norris and L T Kurland, p 12. New York, Grune and Stratton, 1969.

5 British Medical fournal, 1976, 1, 1422.

6 Smith, R A, and Norris, F H, fournal of the American Medical Association, 1975, 234, 715 .

7 British Medical fournal, 1971, 2, 40.

${ }^{8}$ Furukawa, T, and Toyokura, Y, Lancet, 1976, 1, 862.

- Adams, M R, Fournal of Speech and Hearing Disorders, 1966, 31, 274.

10 Goode, R L, and Smith, R A, Laryngoscope, 1970, 80, 1078.

11 Jokelainen, M, and Palo, J, Lancet, 1976, 1, 1246.

\section{Beyond Calais}

Doctors whose native tongue is English find it difficult enough to write good medical articles, and for English translators of foreign language texts and foreigners writing English articles the difficulties are even greater. Professor Peter Newmark ${ }^{1}$ has recently given some tips to translators: translate the title last unless it clearly names the subject of the article; read the bibliography early on-English titles should give clues about the key words being used in the text; don't use a bilingual or multilingual dictionary as the only authority, because they have so many superfluous words; and read through the whole article before starting, during translation, and on completion.

Direct translation is often impossible. "Chronic bronchitis," and "peptic ulcer," for instance, have quite different meanings in English, French, and German. Eponyms such as Pott's disease complicate matters, as several nations often claim the same test, theory, or syndrome for their own compatriots. An example is Graves's disease, which in French becomes "la maladie de Basedow," in Italian "la malattia di Flaja," and in German "Glotzaugenkrankheit." Elsevier's Medical Dictionary gives 42 different terms in five languages for hyperthyroidism. And what do you do about diseases with more than one name in English: do you choose mumps or epidemic parotitis, measles or morbilli ? Drugs, of course, are marketed under different trade names in different countries and their names always have to be checked. Fortunately English medical style is simpler than French or German and tends to use words in everyday use. Even so, Professor Newmark points out that it is not as simple as all that: in French and German, for example, there is no word for knuckle; in French, none for shin; and the Russians do not distinguish between hand and arm.
In addition to medical terms, the translator also has to convey to the reader the same meaning and emotional impression that he imagines (clearly he cannot know for certain) the original writer produced on his own reader. He also has to remove barbarities of style; clarify and abridge; check for inaccuracies and misspellings; and, in general, make the article readable and interesting. Nevertheless, there can be no iron rule about language. There is much more uniformity of style among journals in Britain than on the Continent: they are less flowery than the French (and presumably, because of this, compress more information into a smaller space) and less academic than the Germans. English sentences usually have objects as subjects, in most main clauses they use passive verbs, and the stress is on verbal nouns rather than verbs and nouns. Unlike other technical languages they try to avoid the multiple noun compound, though these do occasionally slip in and one may find sextuple noun compounds such as "baseline cadaver-kidney transplant survival rate."

The task facing a medical translator is formidable, but no greater than that of the brave foreigner who tries to write his medical article in English (but how well many of them succeed). His general English will have to be idiomatic and his vocabulary extensive and up to date, but there are many pitfalls for the unwary. ${ }^{2}$ In French, for instance, the groin is l'aine and le groin means snout of a pig or boar; our anthrax is le charbon, but their l'anthrax means a cluster of boils; il s'abuse means he is mistaken; the pelvis is le bassin; and un éditeur is a publisher (an editor being un rédacteur). Whimster's ${ }^{3}$ experience with Finnish and other Nordic authors has provided many examples of charming non-existent words creeping in, such as "subfebrility," "unprecise," and "fallacity," and obsolete words like "semiology" (for "symptomatology") and "ulcus ventriculi."

American English, too, often needs translating, as the recently published The Language of Medicine $e^{4}$ shows, though similar faults are often found in articles by English authors. VD or ESR, for example, will be understood by most Englishmen, but American abbreviations such as WDWNWM c/o SOB (jargon for well-developed and well-nourished white male complaining of shortness of breath) are unlikely to be understood by Europeans. Their truncated forms of words may also lead to confusion-(electro)lytes, multip(ara), (electrocardio)gram, osteo(myelitis)-while their gobbledygook includes summarisation for summary, and osseous structures for bones.

Thoreau's plea to "simplify, simplify" remains the key to better medical writing, but there are other obstacles to clarity that are self-imposed. A universal uniformity of style in medical journals would help. We may have freed ourselves from the pretentious use of Latin and Greek (and no longer claim, like Gibbon "My English text is chaste, and all licentious passages are left in the decent obscurity of a learned language"), but we carry an ever-increasing burden of synonyms, eponyms, acronyms, and technical jargon. While these may be essential in describing methods and results, they should be kept to a minimum in descriptive writing. The single common characteristic of great medical writers from Hippocrates onwards has been that they are easy to read. If it's hard going, it's almost always second class.

\footnotetext{
1 Newmark, P P, The Incorporated Linguist, 1976, 15, 41-7, 63-7.

2 Farfor, J A, and Benhamou, J P, Lancet, 6 October to 3 November 1973, $788,840,901,959,1018$.

3 Whimster, W F, in Lock, S, Thorne's Better Medical Writing, 2nd edn, London, Pitman Medical (in press)

4 Dirckx, J H, The Language of Medicine. Maryland, Harper \& Row, 1976.
} 